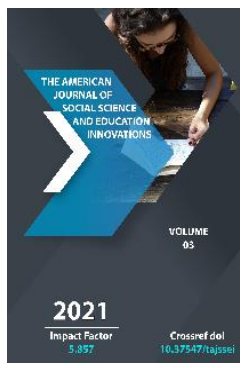

\title{
Confidence and its Connection to Demography Influence
}

\author{
Asher Mirada \\ Professor, Department Of Social Sciences, Yasouj University, Iran
}

Journal Website:

http://usajournalshub.c om/index,php/tajssei

Copyright: Original content from this work may be used under the terms of the creative commons attributes 4.0 licence.

\section{ABSTRACT}

Problem proclamation: Social confidence is the primary topic in the public activity. Confidence is "the assumption that emerges inside a local area of standard, legit and agreeable conduct, in view of regularly shared standards". Advancement, social confidence and security are interlaced classifications and have cooperation to one another. Social confidence, as a primary factor in friendly capital, gives social setting to formative projects. This investigation, analyze the effect of Demography variables on the social confidence to other people. As friendly confidence is a vital factor in friendly connection, this investigation is expected to assess such factor as indicated by segment influence. Approach: This examination has been done on existing information about Iranian qualities and mentalities. A few influence like sexual orientation, age, schooling level, work circumstance, conjugal circumstance have been concentrated in this examination. A portion of these influence like training, correspondence to advancement level, particularly in friendly turn of events. Results: Findings of this examination demonstrated that there is huge connection between all of autonomous influence (Gender, age, training level, work circumstance, conjugal circumstance) and social confidence to families and family members, there is critical connection between influence like sexual orientation, schooling level, work circumstance, conjugal circumstance (free influence) and social confidence to companions. Investigating the information showed that, the occupants of less and more created urban areas have distinctive circumstance in confidence. End/Recommendations: This examination presents three kinds of confidence upon the advancement level of social orders. Confidence in Iran is an illustration of confidence structure in creating social orders.

\section{KEYWORDS}

Sociology social confidence, advancement, segment influence, segment influence 


\section{INTRODUCTION}

Social confidence is one of the basic subjects in contemporary humanism, which has been considered as one of the social capital pointers. Human existence is separated from different creatures by accomplished and social practices. Social confidence is one of the basic and facilitator components of human relations. Its circumstance in every general public could be lead to assembly and uniqueness among people and human networks. There are different degrees of social confidence toward people, gatherings, establishments and diverse social classes in every general public. These degrees of social confidence might be changed during the social, social, political and financial changes. Modernization measure has influenced the social and monetary constructions of various social orders. These progressions have significant results in social and social constructions. Iran culture, too, has acknowledged social changes which, partially, have changed the social relations and social confidence. During the previous century all components of Iran culture influenced by modernization measure, straightforwardly or by implication.

\section{MATERIALS AND METHODS}

Utilizing the Survey information, the exploration strategy for this investigation is second examination technique. Also, exploring the speculations and studies is done in this investigation. This study has been done in the capital of areas in Iran. As there are various territories upon formative levels, this examination is to assess the confidence degree in various improvement based regions. The vast majority of respondents were youthful and the greater part of them were single. Choosing the two urban communities from all urban communities has been done because of various degrees of advancement in Iran urban communities. As Iran is a creating society where could be followed the less and more created networks and urban communities, in this investigation the information of moderately two distinct urban communities have been thought about in a second examination strategy.

Utilizing the Survey information, the exploration strategy for this investigation is second examination technique. Furthermore, exploring the speculations and studies is done in this examination. This overview has been done in the capital of regions in Iran. As there are various territories upon formative levels, this investigation is to assess the confidence degree in various improvement based regions. In the Socio-social characteristics of respondents have been advertised. As information show, the majority of respondents were youthful and a large portion of them were single. Choosing the two urban communities from all urban areas has been done because of various degrees of advancement in Iran urban areas. As Iran is a creating society where could be followed the less and more created networks and urban areas, in this examination the information of generally two distinct urban communities have been analyzed in a second investigation technique. 
Haitian and Saran in their examination "Confidence in Virtual Universities" have considered the confidence in new sort of colleges. This investigation showed that understudies with low confidence in virtual colleges might be more averse to select removed learning courses. Numerous variables add to understudy's confidence level, including view of the virtual college's nature of instruction, educator's abilities, scholastic standing, and so forth. This examination analyzed five components (scholastic standing, managerial viability, size of establishment, reasonably educational cost and Suitable ecological Conditions) as precursors and three influenceas outcomes of understudy's confidence. The connections among influence were resolved utilizing an underlying conditions model and way investigation. Our examination recommends that the scholarly standing and the Suitable natural Conditions for action a virtual college are the main determinants of understudy's confidence. Besides, the understudy's confidence level essentially influences understudy's readiness to concentrate in virtual colleges.

\section{DISCUSSION}

Confidence as a central issue in human existence, have different measurements and, as a rule, being influenced by various influence. This investigation which has been done upon the second examination of Iran National worth overview, show that confidence in Iran culture is distinctive among individuals agreeing Demography components. The information of two unique urban communities of Iran, Isfahan and Saharan, more and less created urban areas, individually, broke down in this examination. As Fukuyama brought up, confidence is a primary and fundamental factor for social fortitude. This examination showed that there is huge distinction between two referenced urban areas as far as confidence to other people. The respondents of less created city, Saharan, have proclaimed more confidence to others than Isfahan.

\section{CONCLUSION}

Investigating the information showed that, inhabitants of the less and more created urban communities have distinctive circumstance in confidence. This examination presents three kinds of confidence upon the improvement level of social orders. Confidence in Iran is an illustration of confidence structure in creating social orders. Less standardized standards and qualities which reporter to creating social orders, is found in this general public. Along these lines, this examination proposes strengthening of inhabitants of less created territories for accomplishing the organized confidence to other people. As confidence is a vital factor in friendly and financial turn of events, it is important to improve the cutting edge markers of advancement in less created social orders.

\section{REFERENCES}

1. Alpu, O. what's more, G. Kurt, 2014. The impact of financial and segment influence on preventative use and initiated fetus removal in Turkey. Am. J. Applied Sci., 1: 332-337.

2. D'Silva, J.L., H.A.M. Shaffril, J. Uli and B.A. Samah, 2011. Socio-Demography influence 
The American Journal of Social Science and Education Innovations (ISSN - 2689-100x)

Published: April 17, 2021 | Pages: 71-74

Doi : https://doi.org/10.37547/tajssei/Volumeo3Issue04-10

2021: 5.857

OCLC - 1121105668

that impact youth mentality towards contract cultivating.

3. Fukuyama, F., 1998. Confidence: The Social Virtues and the Creation of Prosperity. first Edn., Free Press, New York, pp: 404. 